ZOOLOGIA 32 (3): 179-186, June 2015

http://dx.doi.org/10.1590/S1984-46702015000300001

\title{
The use of pelvic fins for benthic locomotion during foraging behavior in Potamotrygon motoro (Chondrichthyes: Potamotrygonidae)
}

\author{
Akemi Shibuya ${ }^{1,2, *}$, Marcelo R. de Carvalho', Jansen Zuanon² \& Sho Tanaka ${ }^{3}$ \\ 'Departamento de Zoologia, Instituto de Biociências, Universidade de São Paulo. Rua do Matão, Travessa 14, 101, \\ 05508-090 São Paulo, SP, Brazil. \\ ${ }^{2}$ Coordenação de Biodiversidade, Instituto Nacional de Pesquisas da Amazônia. Avenida André Araújo 2936, Aleixo, \\ 69060-001 Manaus, AM, Brazil. \\ ${ }^{3}$ School of Marine Science and Technology, Tokai University. 3-20-1 Orido, 424-8610, Shimizu, Shizuoka, Japan. \\ "Corresponding author. Email: akemi_shibuya@yahoo.com.br
}

\begin{abstract}
Synchronized bipedal movements of the pelvic fins provide propulsion (punting) during displacement on the substrate in batoids with benthic locomotion. In skates (Rajidae) this mechanism is mainly generated by the crural cartilages. Although lacking these anatomical structures, some stingray species show modifications of their pelvic fins to aid in benthic locomotion. This study describes the use of the pelvic fins for locomotory performance and body reorientation in the freshwater stingray Potamotrygon motoro (Müller \& Henle, 1841) during foraging. Pelvic fin movements of juvenile individuals of $P$. motoro were recorded in ventral view by a high-speed camera at 250-500 fields $/ \mathrm{s}^{-1}$. Potamotrygon motoro presented synchronous, alternating and unilateral movements of the pelvic fins, similar to those reported in skates. Synchronous movements were employed during straightforward motion for pushing the body off the substrate as well as for strike feeding, whereas unilateral movements were used to maneuver the body to the right or left during both locomotion and prey capture. Alternating movements of the pelvic fins are similar to bipedal movements in terrestrial and semi-aquatic tetrapods. The pelvic fins showed coordinated movements during feeding even when stationary, indicating that they have an important function in maintaining body posture (station holding) during prey capture and manipulation. The use of pelvic fins during prey stalking may be advantageous because it results in less substrate disturbance when compared to movements generated by pectoral fin undulation. The range of pelvic fin movements indicates more complex control and coordination of the pelvic radial muscles.
\end{abstract}

KEY WORDS. Behavior; Elasmobranchii; locomotor adaptation; potamotrygonid stingrays; swimming.

Contrasting with most sharks, which mainly use axial and caudal fin movements during locomotion, batoids tend to use undulation or oscillation of the pectoral fins as their primarily locomotory mode. Movements by undulation are prevalent in many batoid groups, such as dasyatid and rajid species, whereas oscillatory movements are predominant among more derived stingrays (Rhinopteridae and Mobulidae) (Rosenberger \& Westneat 1999, Rosenberger 2001). Even though the role of the pectoral fins during swimming is well documented in batoids, the specific role of the pelvic fins in the locomotion of many species is unknown. However, they are known to play an important role in swimming and body maneuvering in batoids, especially during benthic locomotion (Holst \& Bone 1993, Lucifora \& Vassallo 2002, Macesic \& Kajiura 2010, MACESIC et al. 2013).

Information about the morphological and functional characteristics of the pelvic fin rays is available especially for species of Rajidae (HolsT \& Bone 1993, LuCIFORA \& VASSALlo 2002, Koester \&Sirito 2003). The morphology of the pelvic fins of skates differ from most batoids in that they have a pronounced notch or concavity on the external fin margin that separates it into two sets of lobes, anterior and posterior. The anterior lobes are internally supported by "crurae", which are formed by the enlarged (or compound) first radial element and four subsequent smaller radials (Fig. 1) that are covered by musculature, connective tissue and skin, and articulate directly with the lateral aspect of the puboischiadic bar. In contrast, the posterior radials articulate directly with the basipterygium and are separated from the anterior, compound radial by a small gap. Crurae are used to "walk" or to perform punt movements (forward movement that includes both thrust and glide/recovery phases of pelvic fins) on the substrate (HOLST \& BONE 1993, LUCIFORA \& Vassallo 2002, Koester \& Spirito 2003, Wilga \& Lauder 2004, CARvalho et al. 2006). Crurae may move independently from the rest of the pelvic fins (synchronously, alternatively, or unilaterally), and their movements are similar to those of the legs, assisting in the rotation or repositioning of the body during prey detection and capture (HolsT \& BONE 1993).

2015 | Sociedade Brasileira de Zoologia | www.sbzoologia.org.br | www.scielo.br/zool All content of the journal, except where identified, is licensed under a Creative Commons attribution-type BY-NC. 
A. Shibuya et al.
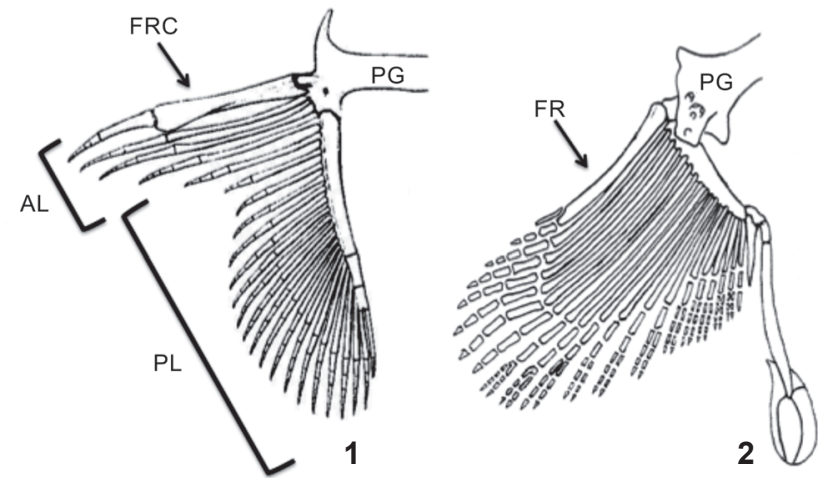

Figures 1-2. Pelvic fin skeleton of the skate Rioraja agassizi (Müller \& Henle, 1841) (1), modified from Garman (1913: plate 53), showing anterior $(\mathrm{AL})$ and posterior $(\mathrm{PL})$ pelvic fin lobes. Potamotrygon sp. (2), modified from Carvalho et al. (2004, Fig. 16), presents a more simple pelvic skeleton. (FR) First radial element of pelvic fin, (FRC) first radial element of crura, (PG) pelvic girdle.

According to Holst \& Bone (1993) and Lucifora \& Vassallo (2002), the use of pelvic fins during prey detection might enhance feeding performance by reducing disturbances that commonly result from pectoral fin movements (and that may elicit a fleeing response by prey). KoesTER \& SPIRITo (2003) stated that when the crurae are used during foraging the pectoral fins do not have to be used, thus eliminating water displacement. Furthermore, the pectoral fins may stimulate the mechano and electrosensory receptors (Lorenzini ampullae and lateral line neuromasts), distorting the electro-mechanosensing field generated by any potential prey (MONTGOMERY \& BODZNICK 1999). Information on the locomotory modes of Neotropical freshwater stingrays (Potamotrygonidae) is available only for a few species and is insufficient. Garrone-Neto \& Sazima (2009) observed that Potamotrygon motoro (Müller \& Henle, 1841) and $P$. falkneri Castex \& Maciel, 1963 in the field undulate their pectoral fins in the bottom to uncover buried prey. However they do not mention the movement of the pelvic fins, which may be employed during foraging to decrease disturbance of the benthos, thus allowing for prey detection by the lateral line canals (Rosenberger 2001, Shibuya et al. 2010, 2012). Later, Macesic et al. (2013) observed that $P$. orbignyi (Castelnau, 1855) uses both pelvic and pectoral fins during punting movements. The structure of the pelvic fin in potamotrygonids (e.g., CaRvalHo et al. 2004, Fig. 16) is quite simple when compared to rajids, since it does not present a discrete anterior lobe or crura that could be used for punting (Fig. 2). Moreover, the role of the pelvic fins in potamotrygonid species may show different patterns when compared to other batoids due to the diversity of substrate types that they use during foraging (flooded forest, presence of litter, muddy, sandy and rocky bottoms) (Araújo et al. 2004). Nevertheless, detailed observation of pelvic fin movements of stingrays in their natural habitats is frequently difficult due to the ventral location of these structures as well as the turbid waters of some South American rivers in which they occur. This study, therefore, aims to describe different types of pelvic fin movements used by individuals of $P$. motoro for locomotion and reorientation of the body during foraging behavior. Moreover, $P$. motoro is a benthic-dwelling ray (e.g., LonARDONI et al. 2006, SHibuYa et al. 2009), as are the species studied by MaCESIC \& KajIURA (2010), whose data are used for comparisons. Potamotrygon motoro was chosen due to its abundance in Neotropical rivers, its occurrence in association with different types of substrates, and the fact that it is easy to maintain and observe in captivity.

\section{MATERIAL AND METHODS}

Two juveniles of $P$. motoro $(14.7 \mathrm{~cm}$ and $15.0 \mathrm{~cm}$ disc width [DW], both males) were obtained from the ornamental fish trade (precise origin of specimens unknown). For comparison, one juvenile of Dasyatis akajei (Müller \& Henle, 1841) $-16.0 \mathrm{~cm}$ DW, male - was provided by local fishermen in Japan and used to measure the extent (protraction/retraction) of pelvic fin movements associated with punting during the thrust phase. All specimens were housed in the Department of Marine Biology of Tokai University (Shimizu, Japan). Acclimation lasted two days before the experiments began. Stingrays were individually maintained in a $120 \times 60 \times 60 \mathrm{~cm}$ acrylic aquarium with water at $26 \pm 1^{\circ} \mathrm{C}$ (controlled by a thermostat), and photoperiod of 10:14 h (light/ dark). Each stingray was fed 8-10 live shrimps (prey size varied from 3-4 cm total length) once a day, offered at regular time intervals and while lights were on. Pelvic fin movements during prey localization and strike behaviors were video recorded in 250 and 500 fields $/ \mathrm{s}^{-1}$ using a Phantom high speed camera (v4.2) with the aquarium illuminated by a $500 \mathrm{w}$ quartz-halogen light. A 50 × $50 \mathrm{~cm}$ mirror was positioned at a $45^{\circ}$ angle beneath the aquarium to allow the observation of movements from below. Sand was not put in the bottom of the tank to allow a clear view of the pelvic movements.

Twenty-eight video recordings (13 for P. motoro and 15 for D. akajei) were captured in three days. Images were initially stored in the camera's internal memory and later transferred to a computer and digitized by Phantom software. The maximum recording for this camera is $16 \mathrm{~s}$ for sequences at 250 fields/ $\mathrm{s}^{-1}$ and $8 \mathrm{~s}$ for sequences at 500 fields $/ \mathrm{s}^{-1}$. The same software was employed to generate the figures that illustrate this study. Timing of each movement in the video sequences was calculated in milliseconds ( $\mathrm{ms}$ ) from the digitized images, or by counting field by field (one field $=4 \mathrm{~ms}$ and $2 \mathrm{~ms}$ in 250 and 500 fields/ $\mathrm{s}^{-1}$, respectively), following MoтTA et al. (2002). The types of pelvic fin movement were defined according to Holst \& Bone (1993) and Koester \& SPirito (2003), as synchronous, alternating and unilateral (maneuvering to the right or to the left). Synchronous refers to the cyclic activity of the pelvic fins (thrust and glide for both fins simultaneously) pushing off the bottom for forward motion. Alternating refers to the "walking" movement, moving the pelvic fins independently and asymmetrically over the substrate. Unilateral movement is used 
to maneuver the body (to the left or right), when one fin acts as a pivot while the other generates the thrust.

Additional information on pelvic fin movements was obtained from experimental observations carried out on three juvenile individuals of the undescribed Potamotrygon sp. (known as "cururu"; $12 \mathrm{~cm} \mathrm{DW}$ ) and one P. motoro ( 18 cm DW), both from the Rio Negro basin. The acrylic aquarium (95 x 45 x 45 $\mathrm{cm}$ ) platform was covered by a thin layer of sand (about $1 \mathrm{~cm}$ deep), simulating the substrate of the freshwater environment. The thin layer of sand on the bottom did not impair observation of the pelvic fin movements.

The software Image (RASBAND 1997, open access) was used to estimate the speed and distance of movements in punt locomotion (synchronous pelvic fin movement); results of the cited variables are presented in disc length (DL and DL/s).

For comparisons concerning the extent of pelvic fins movement (protraction/retraction) during the thrust phase, the schematic figures of MACESIC \& KAJIURA (2010) were analyzed. The term thrust refers to impulse movement for the forward motion of the body, using pelvic fins, combined or not with pectoral fin undulation/oscillation. Punting is the thrust associated with gliding locomotion on the substrate. The extent of the pelvic fins during the thrust phase was calculated in relation to orthogonal lines at the base of the outer margin of the fin (Fig. 3), and measured from the sum of the maximum angles of protraction and retraction of the pelvic fins. The maximum protraction and retraction were calculated from the position between 0 to $90^{\circ}$ and 0 to $-90^{\circ}$, on the horizontal line (from the base of outer margin of the fin), respectively (Fig. 4). Estimated values of the extent of pelvic fins during the thrust phase were also calculated from MaCESIC \& KaJIURA (2010) for each batoid species analyzed. Inferences were made using the cladograms proposed by Carvalho et al. (2004) and McEachran \& Aschliman (2004) since the current comparison strictly focuses on morphological characteristics. However, the recent batoid phylogeny proposed by Aschliman et al. (2012) does not substantially change the phylogenetic inferences underpinning our comparisons.

\section{RESULTS}

All types of pelvic movements previously described for other species were identified in Potamotrygon sp. and P. motoro: synchronous, alternating and unilateral. Observations of the locomotory modes of both species showed similar pelvic fin movements, even on the sandy bottom of the aquarium.

\section{Synchronous movements}

Potamotrygon motoro generated rapid thrust for punting, moving in a straight fashion to capture prey. During punting, the pelvic fins are protracted and move to an anterior position poised on the substrate; they then simultaneously push off to displace the body forward, which occurs concomitantly with the retraction of the fins (Fig. 5). The forward motion of the body to strike prey is generated by the synchronous move-
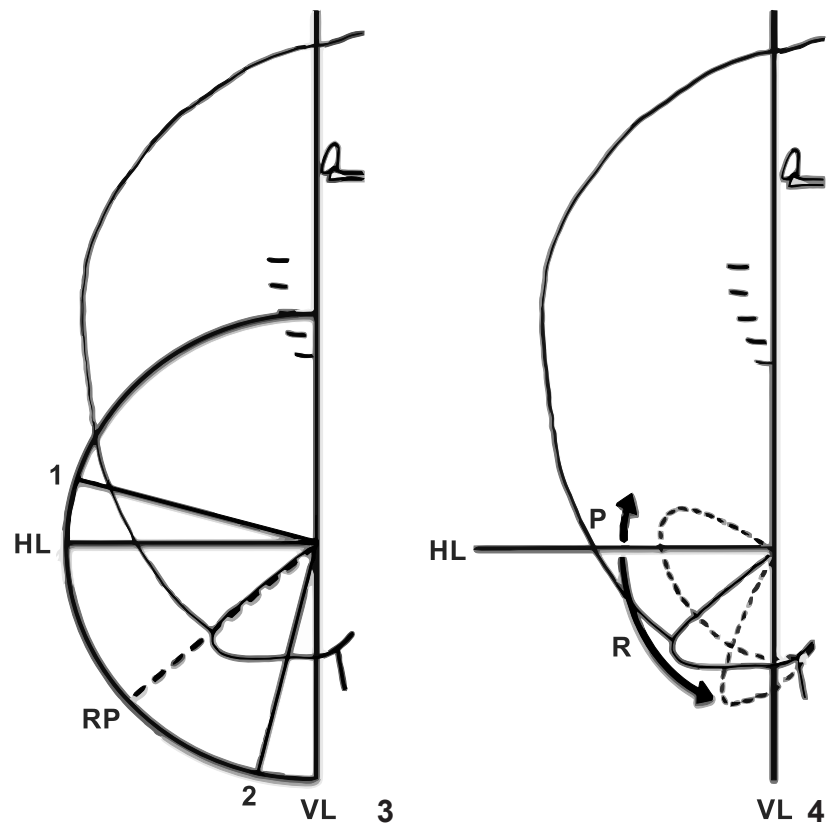

Figures 3-4. The extent of pelvic movement during the thrust phase (3) was measured from the sum of the angles of protraction (P) and retraction $(R)$ relative to a vertical line passing through the point of insertion of the outer margin of the fin. Maximum protraction $(P)$ and retraction $(R)$ of the pelvic fins (4) were calculated in relation to orthogonal horizontal $(\mathrm{HL})$ and vertical $(\mathrm{VL})$ lines centered at the point of insertion of the outer margin of the fin. Dashed line indicates resting position (RP).

ment of the pelvic fins and is supplemented by the undulation of the pectoral fins. The speed was $0.43 \mathrm{DL} / \mathrm{s} \pm 0.15 \mathrm{SD}$ for the striking behavior. The mean distance of the punting movements was $0.11 \mathrm{DL} \pm 0.05 \mathrm{SD}$ until reaching the prey, where locomotion terminated and feeding behavior began.

\section{Alternating movements}

During slow and straightforward motion for foraging behavior, the pelvic fins moved in a way similar to alternating gait bipedalism, comparable to a "walking" movement, which is used during thrust and glide locomotion. This type of movement features anteroposterior alternating motion of the pelvic fins: when one fin is in the anterior position, the other is placed posteriorly (Fig. 6, in 324 and $676 \mathrm{~ms}$ ). To generate thrust, the anteriorly positioned pelvic fin is protracted and maintains support on the substrate, pushing the body ahead in a row-like movement (Fig. 6, in $516 \mathrm{~ms}$ ). During thrust, the opposite (and posteriorly positioned) pelvic fin simultaneously starts moving forward gliding over the substrate. The fin is then moved to an anterior position and rests on the substrate (Fig. 6, in $768 \mathrm{~ms}$ ). The repeated use of this movements results in a slow forward motion while fin position is alternated. The pelvic fin is partially retracted when moved backward during thrust. 

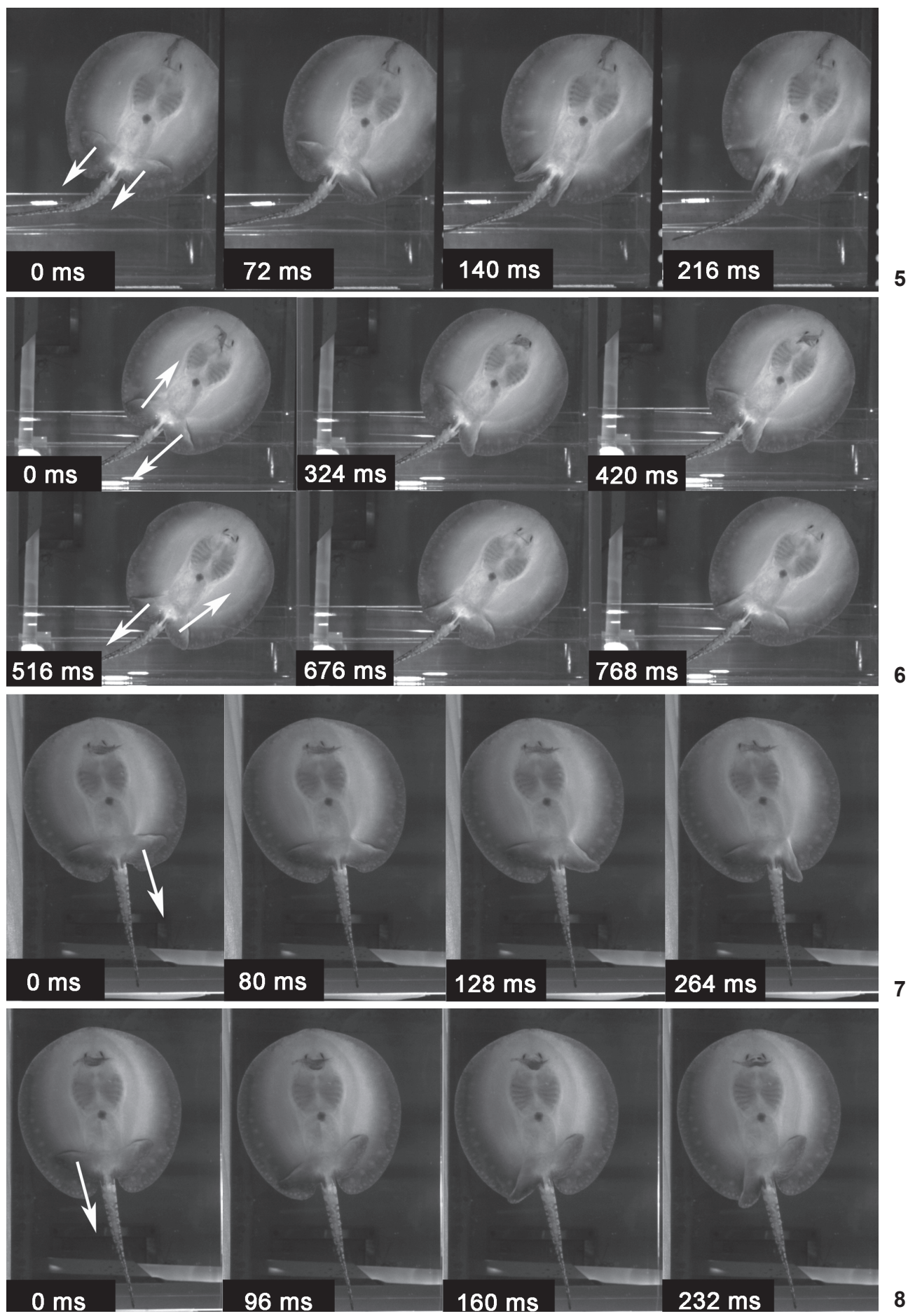

Figures 5-8. Video sequence images illustrating movements of the pelvic fins in Potamotrygon motoro. Arrows indicate direction of fin movements. (5) Synchronous movement thrusts the body forward. (6) Alternating movement of both fins in opposite directions (bipedalism). (7) Unilateral movement of the left fin, turning the body to the right (note the perpendicular position of the right pelvic fin in relation to body axis). (8) Unilateral movement of the right fin, moving the body to the left (the fully protracted and forward position of the left pelvic fin acting as a pivot). Sequential time is indicated in each frame in milliseconds (ms). 


\section{Unilateral movements}

In this type of movement, one of the pelvic fins is employed while its antimere is not engaged in similar movement. In general, such unilateral pelvic fin movements are employed to turn the body slightly to the right or left while maintaining the general body position. When the ray moves its body to the right, its right pelvic fin remains in contact with the substrate, while the left fin pushes the body with one or more row-like movements (Fig. 7). During left turning movements, the left fin is maintained still and the right one assumes the "rowing" role (Fig. 8). The extent of the movement of a pelvic fin in activity may vary during body rotation, with the pelvic fin held in a perpendicular position to the longitudinal axis of the body (Fig. 7 , in $0 \mathrm{~ms}$ ), or conspicuously projected anteriorly (Fig. 8, in 0 ms). This type of movement was usually observed during the final stage of capture, directing the mouth to the prey. Unilateral movement was also employed to capture prey that was positioned laterally to the body of the specimen.

\section{Comparative analysis with other batoids}

The extent of the displacement of the pelvic fins during the thrust phase in $P$. motoro reached an angle of $\sim 87^{\circ}$, whereas the results calculated for other batoid species were: Raja eglanteria Bosc, 1800, $64^{\circ}$; Narcine brasiliensis (Olfers, 1831), $\sim 42^{\circ}$; Urobatis jamaicensis (Cuvier, 1816), $21^{\circ}$, and Dasyatis sabina (Lesueur, 1824), $35^{\circ}$ (Figs. 9-13). Dasyatis akajei showed a low angle of punting (Fig. 14), presenting a total of $\sim 44^{\circ}$ for thrust. The angle of protraction was higher in $R$. eglanteria, however $P$. motoro presented a relatively high angle of retraction of the pelvic fins (Fig. 15). The extent of the pelvic fins during thrust for each cited species is shown in the cladogram for batoid families in Fig. 16.

\section{DISCUSSION}

The variety of pelvic fin movement patterns described for rajid species (Holst \& Bone 1993, Koester \& SPIRITo 2003) were also observed in P. motoro, even in the absence of crurae, which are considered derived for skates (Holst \& Bone 1993, McEachran \& Dunn 1998, Lucifora \& Vassallo 2002, Koester \& SPIRITo 2003). Movements of the separate pelvic fin lobes may therefore be further enhanced by separate and subdivided insertions within both the dorsal and ventral radial muscles for a general account of pelvic fin muscles, see DANIEL (1934) and Marinelli \& Strenger (1959). Crurae are lacking in stingrays (Myliobatiformes), even though the first pelvic radial element is also of a compound nature and articulates directly with the pelvic (puboischiadic) girdle - for additional illustrations of potamotrygonid pelvic fins, see Lovejoy (1996); Carvalho et al. (2004); and Carvalho \& Lovejoy (2011). The pelvic musculature in potamotrygonid species described by MACESIC \& KajIURA (2010) is similar to $U$. jamaicensis and D. sabina. The pelvic fins present distal and proximal ventrally positioned

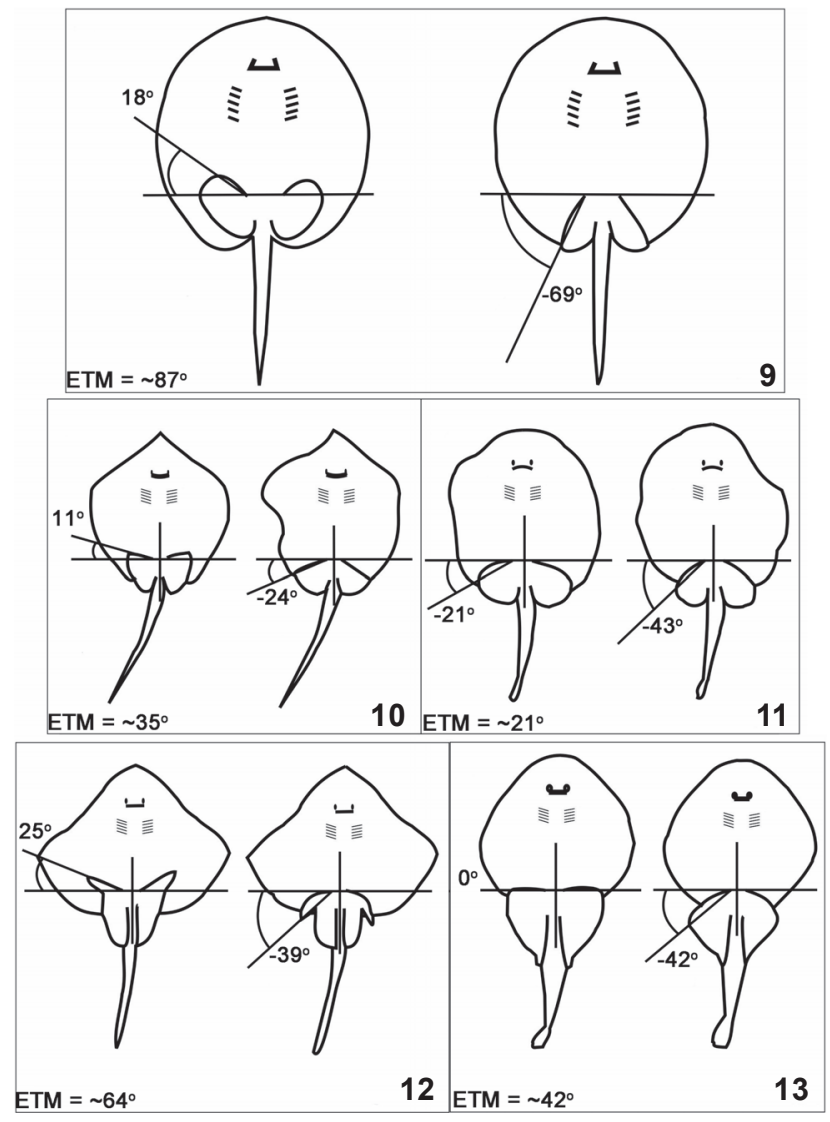

Figures 9-13. The extent of the pelvic fins during the thrust phase. A straight line from the base of outer margin to the tip of the fin was used to calculate the angles of protraction and retraction. (9) Thrust in Potamotrygon motoro starts at an angle of $18^{\circ}$ and reaches $69^{\circ}$, totaling $87^{\circ}$. Potamotrygon motoro was compared to (10) Dasyatis sabina, (11) Urobatis jamaicensis, (12) Raja eglanteria, and (13) Narcine brasiliensis. The total value of the extent of the pelvic fins during thrust phase (ETM) is at the inferior left of each frame. Figures 10-13 from MACESIC \& KAJIURA (2010), reproduced with permission from the authors.

depressor muscles, which act to depress the fins (retraction movement), whereas the dorsally positioned distal and proximal levator muscles protract them. The protractor muscles act to protract the basipterygium, extending the fins anteriorly. The pelvic fin movements exhibited by $P$. motoro may indicate an increased control and coordination of its pelvic musculature to reach a wider angle compared to rajid species. This hypothesis needs to be tested by anatomical and functional comparisons of the dorsal and ventral pelvic muscles. Our investigation, conducted on captive individuals, has generated essential information on the locomotion of potamotrygonid stingrays that would not have been possible in the field (due to the limited view of pelvic fin movements under the body); 

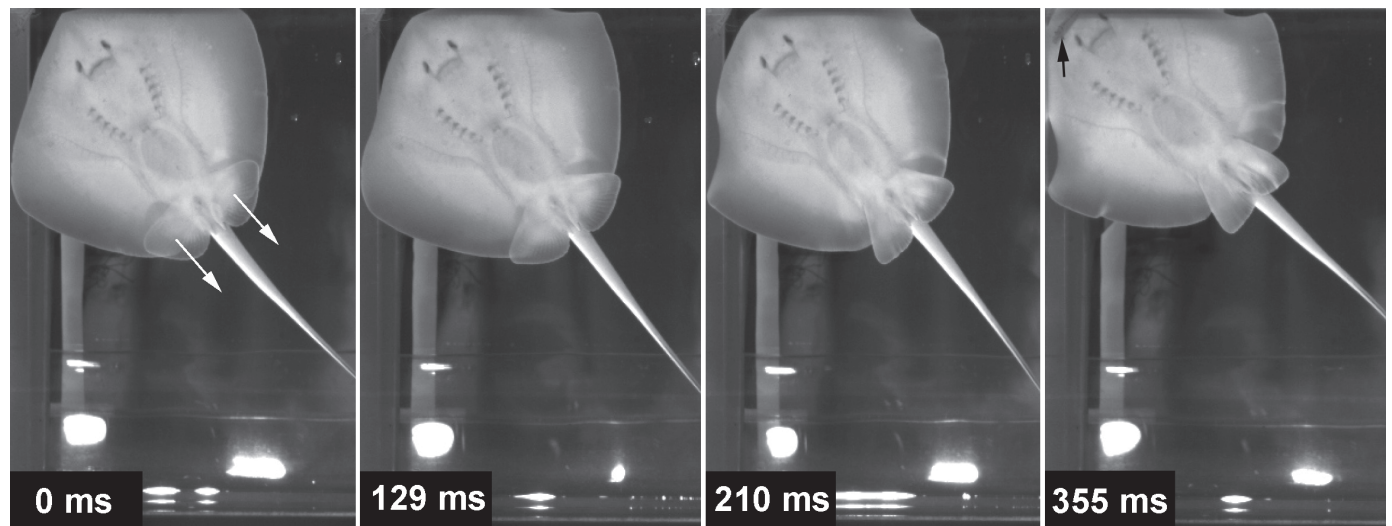

Figure 14. Video sequence images illustrating the punting movement of the pelvic fins in Dasyatis akajei during prey capture behavior Thrust starts at $0 \mathrm{~ms}$ and reaches an angle of about $44^{\circ}$ (in $355 \mathrm{~ms}$ ). Sequential time is indicated in each frame in milliseconds (ms). Black arrow indicates position of prey.

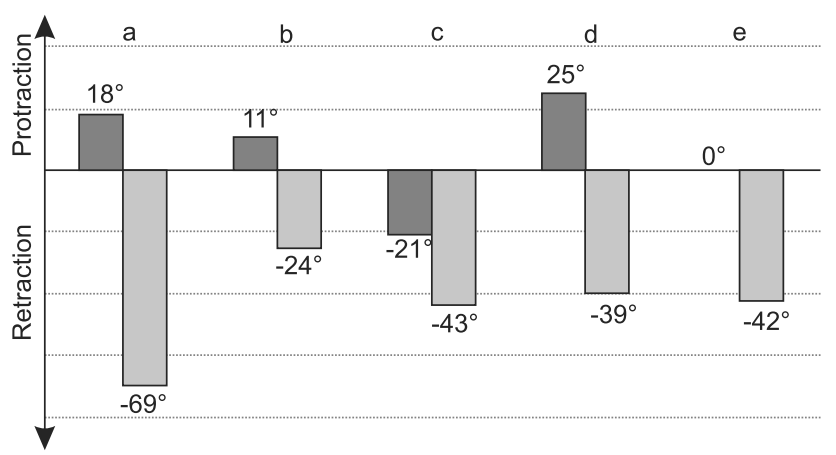

Figure 15. Graphic representation of the maximum extent of the pelvic fins during thrust phase, comparing Potamotrygon motoro (a) to (b) Dasyatis sabina, (c) Urobatis jamaicensis, (d) Raja eglanteria, and (e) Narcine brasiliensis - from MACESIC \& KAJIURA (2010).

the pelvic movements were similar to those observed in the experiments with sand in the bottom of the aquarium.

Our observation on the feeding behavior of $P$. motoro under captive conditions revealed that both pelvic and pectoral fins are employed simultaneously to allow fast prey strike, combining synchronous movements of the pelvic fins with pectoral undulation. The punt movement was observed only during feeding behavior, indicating that it is used mainly for striking the prey just before it is captured; the pelvic fins may not necessarily protract entirely to generate thrust. Unilateral and alternating movements of the pelvic fins provide a fine control of the body during prey capture behavior, positioning the body over the prey and directing the mouth to grasp it (SHIBUYA et al. 2012). The guidance is generated by the paired fins and act together during foraging behavior, and the pelvic fins seem to be essential for oral prey manipulation, whereas the pectoral fins prevent it from escaping (by keeping the prey under the body of the ray). Even without a substrate (thin layer of sand) in the aquarium, individuals of $P$. motoro seem to have no difficulty using pelvic movements (synchronous, alternating and unilateral) on the presumably slippery bottom. This evidence suggests that $P$. motoro may use "walking" movements on different types of substrates (including unconsolidated ones, such as sand, mud, and leaf litter banks; cf. Araújo et al. 2004), since it does not depend on a firm grip to produce forward thrust maneuvering through small obstructions while searching for prey (such as crabs and small fishes) (Shibuya et al. 2009).

Despite the intermediate speed of augmented punting in P. orbignyi $(0.26 \mathrm{DL} / \mathrm{s})$ (MACESIC et al. 2013), compared to slow synchronized pelvic movement $(\sim 0.20 \mathrm{DL} / \mathrm{s}$, U. jamaicensis and D. sabina) and fast true punters $(\sim 0.40 \mathrm{DL} / \mathrm{s}, R$. eglanteria and $R$. radula) (Macesic \& Kajiura 2010, Bilecenoglu \& Ekstrom 2013), P. motoro is fast ( $\sim .43 \mathrm{DL} / \mathrm{s})$, probably as a consequence of its foraging behavior to capture prey; the usual synchronized swimming is probably slower. The low distance traveled by $P$. motoro can possibly be explained by the abrupt cessation of locomotion to capture prey during feeding behavior. It is possible that the absence of sand in the bottom of the aquarium changes the subject's locomotion, requiring the pelvic fins to be more effective to avoid a slippery gait; however, a sandy substrate increases drag during movement, decreasing the effort the individual needs to generate for punting. Potamotrygon sp. ("cururu") presents the same pelvic fins movements (synchronous, alternating and unilateral) and a similar extension of the pelvic fins during thrust, reinforcing that the examined potamotryonid species may thrust their pelvic fins wide.

Crurae do not occur in potamotrygonid stingrays and this group is phylogenetically positioned in a more "derived" position compared to skates (McEachran \& Aschliman 2004); however, their pelvic fins have a wide extent during the thrust phase when compared to U. jamaicensis and D. sabina (MACESIC $\&$ KajIUra 2010). The extent of the movements of the pelvic fins (protraction/retraction) found in $P$. motoro were also observed in Potamotrygon sp. (A. Shibuya pers. obs.). 


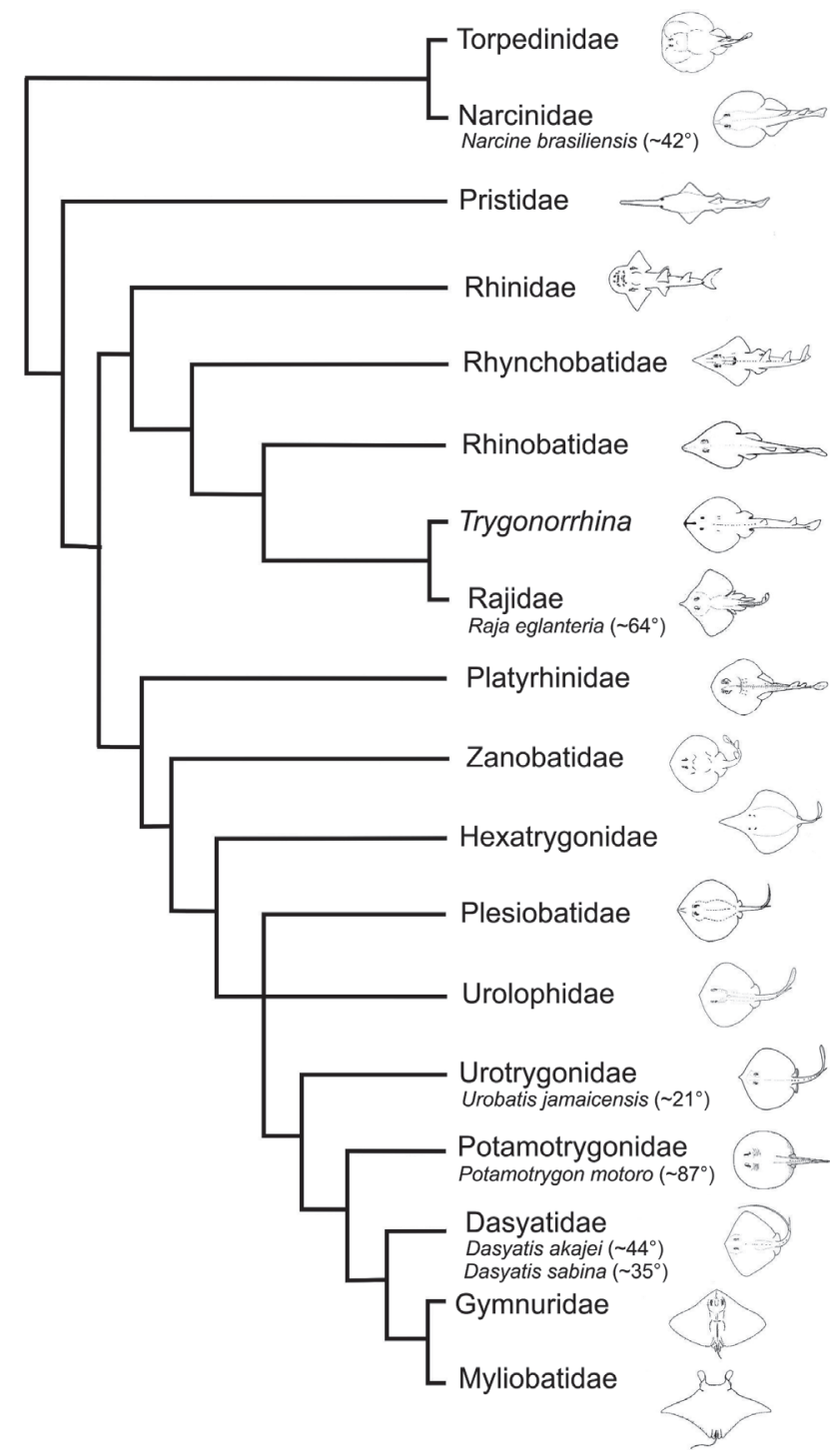

Figure 16. Distribution of the extent of pelvic movements during the thrust phase in batoid species analyzed by MACESIC \& KAJIURA (2010) with the inclusion of Potamotrygon motoro (Potamotrygonidae) in an adapted and simplified cladogram from CARVALHO et al. (2004) and McEachran \& Aschliman (2004).

Even though a low number of batoid species has been analyzed thus far, the thrust of the pelvic fins seems to decrease from "true punters" (which primarily use pelvic fin locomotion) to "augmented punters" (which predominantly use pectoral fin locomotion) (Macesic \& KaJIURA 2010). Nevertheless, considering the current results, $P$. motoro stands out with a comparatively much greater angle during the thrust phase, as in true punters. However, this species also uses the pectoral fins for swimming synchronously with the pelvic fins. Potamotrygon motoro uses the coordination of both pelvic and pectoral fins for locomotion, which was also observed in the augmented punter P. orbignyi (MACESIC et al. 2013). Despite the fact that $P$. motoro travels faster than $P$. orbignyi, its velocity is comparable to true punters, but due to the synchronized use of pelvic and pectoral fins, P. motoro is considered an augmented punter. The potamotrygonid lineage is the sister group of the clade Dasyatidae + (Gymnuridae + Myliobatidae) (CARvalHo et al. 2004, McEachran \& Aschliman 2004). However, the high angle of the pelvic fins during the thrust phase may not strictly follow the evolution of batoid groups, as more data are required concerning pelvic fin movements in species of other groups.

Juveniles of some potamotrygonid species, such as $P$. motoro, and the small-sized Potamotrygon sp. from the Rio Negro, are able to occupy habitats such as flooded forests, where large amounts of tree trunks, fallen branches and other debris may impair free movements over large distances. In such habitats, locomotion using pelvic fin movements seems to be especially important and effective. In addition, unilateral movements of the pelvic fins may be employed for subtle re-orientation of the body during recognition of the surrounding habitat during the initial phases of foraging, as well serving as a defensive tactic to avoid being noticed as a result of substrate disturbance during swimming. However, investigations on the role of pelvic fins in different potamotrygonid species and under different environmental conditions are needed to test this hypothesis.

\section{ACKNOWLEDGMENTS}

The authors would like to thank the students of the Department of Marine Biology (Tokai University, Japan) for taking care of the rays held in the aquariums during the research project. Laura Macesic-Ekstrom provided valuable information about batoid locomotion. We also thank Adriano Oliveira and Carlos Valentim for kindly providing potamotrygonid specimens for additional observation. The first author thanks the Japan International Cooperation Agency (JICA) for financial support and a technical trainee fellowship, and the Conselho Nacional de Desenvolvimento Científico e Tecnológico (CNPq) for a doctoral grant. MRC thanks the Fundação de Amparo à Pesquisa do Estado de São Paulo (FAPESP grant 2012/09877-0, 2012/02349-5 and 2012/05391-5) and CNPq (303061/2008-1, 304615/2011-0) for financial support. JZ thanks the CNPq for grant 313183/2014-7.

\section{LITERATURE CITED}

Araújo MlG, Charvet-Almeida P, Almeida MP, Pereira H (2004) Freshwater stingrays (Potamotrygonidae): status, conservation and management challenges. AC 20 info 8: 1-6. Available online at: http://www.cites.org/common/com/ac/20/E20-inf08.pdf [Accessed: 28/12/2013].

Aschliman NC, Nishida M, Miya M, Inoue JG, Rosana KM, Naylor GJP (2012) Body plan convergence in the evolution of skates and 
rays (Chondrichthyes: Batoidea). Molecular Phylogenetics and Evolution 63(1): 28-42. doi: 10.1016/j.ympev.2011.12.012

Bilecenoglu M, Екsтrom LJ (2013) Pelvic fin walking and punting behaviour of Raja radula Delaroche, 1809 observed in the Sea of Marmara. Mediterranean Marine Science. 14/1: 158161. doi: $10.12681 / \mathrm{mms} .333$

Carvalho MR de, Gomes UL, McEachran JD (2006) First report and description of a legskate, genus Cruriraja, from the southwestern Atlantic ocean (Chondrichthyes: Rajidae). Cybium 30: 343-354.

Carvalho MR De, Lovejoy NR (2011) Morphology and phylogenetic relationships of a remarkable new genus and two new species of Neotropical freshwater stingrays from the Amazon basin (Chondrichthyes: Potamotrygonidae). Zootaxa 2776: 13-48.

Carvalho MR de, Maisey JG, Grande L (2004) Freshwater stingrays of the Green River Formation of Wyoming (Early Eocene), with the description of a new genus and species and an analysis of its phylogenetic relationships (Chondrichthyes: Myliobatiformes). Bulletin of the American Museum of Natural History 284: 1-136.

Daniel JF (1934) The Elasmobranch Fishes. Berkeley: University of California Press, Third edition. 332p.

Garman, S. 1913. The Plagiostomia (Sharks, Skates and Rays). Memoirs of the Museum of Comparative Zoology at Harvard College 36: 1-528.

Garrone-Neto D, Sazima I (2009) Stirring, charging, and picking: hunting tactics of potamotrygonid rays in the upper Paraná River. Neotropical Ichthyology 7(1): 113-116. doi: 10.1590/ S1679-62252009000100015

Holst RJ, Bone Q (1993) On bipedalism in skate and rays. Philosophical Transactions of the Royal Society London B 339: 105-108. doi: 10.1098/rstb.1993.0007

Koester DM, Spirito CP (2003) Punting: An unusual mode of locomotion in the little skate, Leucoraja erinacea (Chondrichthyes: Rajidae). Copeia 2003(3): 553-561. doi: 10.1643/CG-02-153R1

Lonardoni AP, Goulart E, Oliveira EF, Abelha MCF (2006) Hábitos alimentares e sobreposição trófica das raias Potamotrygon falkneri e Potamotrygon motoro (Chondrichthyes, Potamotrygonidae) na planície alagável do alto rio Paraná, Brasil. Acta Scientiarum Biological Sciences 28(3): 195-202.

Lovejoy NR (1996) Systematic of Myliobatoid elasmobranchs: with emphasis of phylogeny and historical biogeography of Neotropical stingrays (Potamotrygonidae: Rajiformes). Zoological Journal of Linnean Society 117(3): 207-257. doi: 10.1111/j.1096-3642.1996.tb02189.x

LuCIFORA LO, VASSALlo AI (2002) Walking in skates (Chondrichthyes, Rajidae): anatomy, behaviour and analogies to tetrapod locomotion. Biological Journal of the Linnean Society 77(1): 35-41. doi: 10.1046/j.1095-8312.2002.00085.x

Macesic LJ, KajIURA SM (2010) Comparative punting kinematics and pelvic fin musculature of benthic batoids. Journal of Morphology 271(10): 1219-1228. doi: 10.1002/jmor.10865
Macesic LJ, Mulvaney D, Blevins EL (2013) Synchronized swimming: coordination of pelvic and pectoral fins during augmented punting by the freshwater stingray Potamotrygon orbignyi. Zoology 116(3): 144-150. doi: 10.1016/j.zool.2012.11.002

Marinelli W, Strenger A (1959) Vergleichende Anatomie und Morphologie der Wirbeltiere: III Lieferung (Squalus acanthias). Vienna, Franz Deuticke Verlag, 305p.

McEachran JD, Aschliman N (2004) Phylogeny of Batoidea, p. 79-113. In: Carrier JC, Musick JA, Heithaus MR (Eds.). Biology of Sharks and Their Relatives. Boca Raton, CRC Press.

McEachran JD, Dunn KA (1998) Phylogenetic analysis of skates, a morphologically conservative clade of elasmobranchs (Chondrichthyes: Rajidae). Copeia 1998(2): 271-290.

Montgomery JC, Bodznick D (1999) Signals and noise in the elasmobranch electrosensory system. The Journal of Experimental Biology 202(10): 1349-1355.

Motta PJ, Hueter RE, Tricas TC, Summers AP (2002) Kinematic analysis of suction feeding in the nurse shark, Ginglymostoma cirratum (Orectolobiformes, Ginglymostomatidae). Copeia 2002(1): 2438. doi: 10.1643/0045-8511(2002)002[0024:KAOSFI]2.0.CO;2

RASBAND WS (1997) ImageJ. Bethesda, U.S. National Institutes of Health. Available online at: http://imagej.nih.gov/ij [Accessed: 28/12/2013].

Rosenberger LJ (2001) Pectoral fin locomotion in the batoid fishes: undulation versus oscillation. The Journal of Experimental Biology 204(2): 379-394.

Rosenberger LJ, Westneat MW (1999) Functional morphology of undulatory pectoral fin locomotion in the stingray Taeniura lymma (Chondrichthyes: Dasyatidae). The Journal of Experimental Biology 202(24): 3523-3539.

Shibuya A, Araújo MLG, Zuanon JAS (2009) Analysis of stomach contents of freshwater stingrays (Elasmobranchii: Potamotrygonidae) from the middle Negro River, Amazonas, Brazil. Pan-American Journal of Aquatic Sciences 4(4): 466-465.

Shibuya A, Zuanon J, Araújo MLG, Tanaka S (2010) Morphology of lateral line canals in Neotropical freshwater stingrays (Elasmobranchii: Potamotrygonidae) from Negro River, Brazilian Amazon. Neotropical Ichthyology 8(4): 867-876. doi: 10.1590/S1679-62252010000400017

ShibuYa A, Zuanon J, Tanaka S (2012) Feeding behavior of the Neotropical freshwater stingray Potamotrygon motoro (Elasmobranchii: Potamotrygonidae). Neotropical Ichthyology 10(1): 189-196. doi: 10.1590/S1679-62252012000100018

Wilga CAD, Lauder GV (2004) Biomechanics of locomotion in sharks, rays and chimeras, p. 139-164. In: CARRIER JC, MUSICK JA, Heithaus MR (Eds.). Biology of Sharks and Their Relatives. Boca Raton, CRC Press.

Submitted: 23 September 2014

Received in revised form: 31 December 2014

Accepted: 23 January 2015

Editorial responsibility: Vinicius Abilhoa 